\title{
PENGARUH LITERASI DIGITAL DAN OPTIMISME TERHADAP KEPEMIMPINAN VISIONER KEPALA SMP KOTA PEKANBARU
}

\author{
Heri Jusnani ${ }^{1)}$ \\ Isjoni $^{2)}$ \\ Daeng Ayub Natuna ${ }^{3)}$ \\ ${ }^{1)}$ Dinas Pendidikan Kota Pekanbaru \\ 2) Lecturer of Education Management Study Programme PPs University of Riau \\ 3) Lecturer of Education Management Study Programme PPs University of Riau \\ E-mail: jusnaniheri@gmail.com
}

\begin{abstract}
This study aims to analyze the effect of digital literacy and optimism on the visionary leadership of junior high school heads in Pekanbaru City. This study used a survey method with a regression approach which was implemented in Pekanbaru City. The research sample was 105 school principals and the data collection technique was done by using a questionnaire. Data analysis was performed using descriptive and inferential statisticsThe results showed a significant influence between digital literacy on visionary leadership, between optimism for visionary leadership and a significant influence between digital literacy and optimism together on visionary leadership. The results of this study can be concluded that the better the digital literacy of the head of SMP in Pekanbaru City, the better the visionary leadership, likewise the better the optimism of the head of SMP in Pekanbaru City, the better the visionary leadership, as well as when together. This research is expected to be useful for improving and increasing the competence of digital literacy and optimism of the principal so that the visionary leadership of the principal will have a real effect on the development of education in schools
\end{abstract}

Keywords: Digital Literacy; Optimism; Visionary Leadership 


\begin{abstract}
ABSTRAK
Penelitian ini bertujuan untuk menganalisis pengaruh literasi digital dan optimisme terhadap kepemimpinan visioner kepala SMP di Kota Pekanbaru. Penelitian ini menggunakan metode survei dengan pendekatan regresi yang dilaksanakan di Kota Pekanbaru. Sampel penelitian adalah 105 orang kepala sekolah dan teknik pengumpulan data dilakukan dengan angket. Analisis data dilakukan dengan menggunakan statistik deskriptif dan inferensial. Hasil penelitian diperoleh pengaruh yang signifikan antara literasi digital terhadap kepemimpinan visioner, antara optimisme terhadap kepemimpinan visioner serta pengaruh yang signifikan antara literasi digital dan optimisme secara bersama-sama terhadap kepemimpinan visioner. Hasil penelitian ini dapat disimpulkan bahwa semakin baik literasi digital kepala SMP di Kota Pekanbaru maka kepemimpinan visioner akan semakin baik, demikian juga semakin baik optimisme kepala SMP di Kota Pekanbaru maka kepemimpinan visioner akan semakin baik, demikian juga bila bersama-sama. Penelitian ini diharapkan dapat berguna untuk memperbaiki dan meningkatkan kompetensi literasi digital dan optimisme kepala sekolah sehingga kepemimpinan visioner kepala sekolah akan berpengaruh nyata terhadap perkembangan pendidikan di sekolah.
\end{abstract}

Kata Kunci: Literasi Digital; Optimisme; Kepemimpinan Visioner

\section{PENDAHULUAN}

Secara operasional pendidikan bertujuan untuk mengembangkan potensi peserta didik agar menjadi manusia yang beriman dan bertakwa, berwatak, berakhlak mulia, sehat, berilmu, cakap, kreatif, mandiri, dan menjadi warga negara yang demokratis serta bertanggung jawab. Untuk menghasilkan sumber daya manusia yang berkualitas dan bermartabat serta insan Indonesia yang cerdas dan kompetitif, diperlukan pembangunan sektor pendidikan sebagai investasi bangsa yang sangat berharga (education is human investment) dalam memenuhi perkembangan dan tuntutan global dunia pendidikan saat ini. Sejalan dengan itu, Peraturan Menteri Pendidikan dan Kebudayaan RI Nomor 22 Tahun 2020 tentang Renstra Kementrian Pendidikan dan Kebudayaan tahun 20202024 menyatakan "Kementerian Pendidikan dan Kebudayaan mendukung Visi dan Misi Presiden untuk mewujudkan Indonesia Maju yang berdaulat, mandiri, dan berkepribadian melalui terciptanya Pelajar Pancasila yang bernalar kritis, kreatif, mandiri, beriman, bertakwa kepada Tuhan Yang Maha Esa, dan berakhlak mulia, bergotong royong, dan berkebinekaan global".

Menghadapi globalisasi dengan segala perubahan yang sangat cepat, setiap lembaga pendidikan (sekolah) dituntut memiliki kemampuan maksimal agar tetap bisa bersaing dan berkembang sesuai tuntutan zaman. Komponen yang sangat penting untuk menjadi perhatian organisasi atau sekolah adalah masalah kepemimpinan, mengingat kepemimpinan tidak bisa dilepaskan dari bagaimana seseorang menjadi figur krusial dalam organisasinya menuju kesuksesan. Dalam beberapa penelitian yang telah dilakukan oleh para peneliti terdahulu, diantaranya oleh Handayani Timur dkk (2018: 21) yang mendapatkan kesimpulan bahwa kepemim-pinan kepala sekolah berpengaruh terhadap mutu sekolah, maka kepemimpinan kepala sekolah menjadi faktor utama 
terhadap keberhasilan sekolah. Ada beragam gaya kepemimpinan yang bisa dipilih agar lembaga pendidikan (sekolah) mencapai kemajuan. Salah satu model kepemimpinan yang layak untuk dipraktikkan di era perubahan sekarang ini adalah kepemim-pinan visioner.

Perkembangan ilmu pengetahuan dan teknologi sangat pesat, menuntut kepala sekolah untuk mengembangkan kom-petensinya secara berkelanjutan dan memiliki visi yang kuat terhadap kemajuan pendidikan di sekolah. Kepemimpinan visioner kepala sekolah di era Revolusi Industri 4.0 yang menuntut kepala sekolah untuk inovatif dan senantiasa berani menghadapi tantangan dan resiko yang akan terjadi akibat perubahan tersebut. Kepala sekolah hendaknya keluar dari zona aman, untuk melakukan perubahanperubahan demi kemajuan pendidikan di sekolah yang dipimpinnya, termasuk ketika berhadapan dengan pandemi Covid-19 saat ini. Berdasarkan Surat Edaran Mendikbud No. 4 Tahun 2020 tentang Pelaksanaan Kebijakan Pendidikan dalam Masa Darurat Penyebaran Covid-19, dimana pembelajaran dialihkan dari belajar di sekolah menjadi belajar dari rumah, bekerja di rumah yang menyebabkan kepala sekolah tidak dapat berinteraksi secara langsung kepada guru dan tenaga administrasi lainnya. Khusus di Kota Pekanbaru, berdasarkan instruksi Wali Kota Pekanbaru, belajar sementara bisa di rumah (Riaupos.com. 2020). Situasi ini sangat mengharapkan hadirnya sosok kepala sekolah yang memiliki kemampuan literasi digital dan optimisme dalam mencari solusi terkait hambatan dan permasalahan yang terjadi pada kegiatan pembelajaran dan penilaian di sekolah yang dialihkan ke rumah.

Menurut Nurul Hidayah (2016: 80-

83) peran kepemimpinan visioner mencakup 4 (empat) peran yaitu: a) penentu arah, pemimpin yang memiliki visi berperan sebagai penentu arah organisasi. Sebagai penentu arah, seorang pemimpin menyiapkan visi, mengomunikasikannya, memotivasi pekerja dan rekan, serta meyakinkan orang bahwa apa yang dilakukan merupakan hal yang benar, dan mendukung partisipasi pada seluruh tahap usaha menuju masa depan, b) agen perubahan, dalam perannya sebagai agen perubahan, pemimpin visioner bertanggung jawab untuk merangsang perubahan di lingkungan internal, c) juru bicara, seorang pemimpin efektif adalah juga seorang yang mengetahui dan menghargai segala bentuk komunikasi yang tersedia, guna menjelaskan dan membangun dukungan untuk suatu visi masa depan, d) pelatih, pemimpin visioner yang efektif harus menjadi pelatih yang baik.

Salah satu kebijakan prioritas Direktorat Jenderal Guru dan Tenaga Kependidikan Kementerian Pendidikan dan Kebudayaan adalah peningkatan kom-petensi kepala sekolah yang mampu berpikir visioner dalam memimpin dan mengelola sekolahnya. Target utamanya adalah membangun tata kelola dan budaya mutu di sekolah yang berdaya saing tinggi. Kepemimpinan abad XXI bagi kepala sekolah dapat dilakukan dengan beberapa strategi. Pertama, kepala sekolah harus mampu melihat peluang dan potensi yang ada dengan mengidentifikasi masalah di sekolahnya sebagai dasar pengembangan sekolah. Kedua, kepala sekolah dalam perannya sebagai supervisor harus mampu berperan sebagai pemimpin instruksional dalam merancang dan melaksanakan pembelajaran abad XXI sesuai dengan konsep pendekatan keterampilan berpikir tingkat tinggi (higher order thinking skills). Ketiga, kepala sekolah sebagai pemimpin pendidikan abad XXI harus mampu mengajak seluruh pemangku 
kepentingan pendidikan di sekolah baik guru, tenaga kependidikan, maupun orang tua untuk bersama-sama mewujudkan pendidikan yang dinamis sesuai dengan perkembangan Revolusi Industri 4.0. Keempat, kepala sekolah harus memberikan dukungan semangat dan penghargaan kepada guru, tenaga kependidikan, dan peserta didik yang telah mencapai hasil atas prestasi, inovasi, dan pencapaian lain yang membanggakan.

Seorang kepala sekolah yang visioner semestinya telah merancang sejak awal peningkatan mutu sekolah seperti menyusun visi dan misi sekolah yang unggul, menjadi contoh atau rujukan bagi sekolah lain. Hasil penelitian Handarini (2019: 182) menyimpulkan bahwa kepemimpinan visioner kepala sekolah berpengaruh secara signifikan terhadap efektivitas sekolah. Hal ini mengindikasikan efektivitas sekolah salah satunya ditentukan oleh kepemimpinan visioner kepala sekolah. Dengan demikian, semakin baik kepemimpinan visioner kepala sekolah maka efektivitas sekolah akan semakin meningkat. Demikian juga dengan penelitian Bedu dkk (2016: 203) dan Masiaga dkk (2017: 118), yang mendapatkan hasil bahwa adanya pengaruh kepemimpinan visioner kepala sekolah terhadap kinerja mengajar guru SMP N 12 Sigli dan terhadap etos kerja serta motivasi kerja guru di SMP Kabupaten Boalemo. Efektivitas sekolah dan membaiknya kinerja mengajar guru serta meningkatnya etos kerja dan motivasi kerja guru setidaknya menjadi jaminan bahwa mutu sekolah juga menjadi lebih baik dengan adanya kepala sekolah yang memiliki kepemimpinan visioner.

Berdasarkan data Badan Akreditasi Nasional Sekolah dan Madrasah (BANSM) tahun 2019 dan data Dinas Pendidikan Kota Pekanbaru tahun 2020, masih ada SMP di Kota Pekanbaru yang memiliki akreditasi B dan C, bahkan belum terakreditasi. Berdasarkan laporan hasil Monitoring dan Evaluasi Pengawas Sekolah Dinas Pendidikan Kota Pekanbaru tahun 2019, ada beberapa SMP di Kota Pekanbaru dalam merumuskan visi, misi dan tujuan sekolah yang belum jelas, kurang sesuai dengan kondisi yang ada, dan meniru visi dan misi sekolah lain, sehingga belum menggambarkan originalitas otonomi sekolah (manajemen berbasis sekolah). Selain itu, masih ada kepala sekolah yang belum melakukan monitoring terhadap kinerja guru serta pemantauan kemajuan prestasi siswa secara berkala dan berkelanjutan.

Kenyataannya lain dari gejalagejala yang diamati pada kepemimpinan kepala SMP yang ada di Kota Pekanbaru masih ditemukan kepala sekolah yang belum berwawasan ke depan, kepala sekolah dalam menjalankan tugas hanya sesuai perintah dari atasan dan kurang memikirkan apa yang akan dilakukan untuk visi ke depan sekolah yang dipimpinnya. Selain itu juga, masih ada kepala sekolah yang tidak menjadi agen perubahan yang unggul di sekolah yang dipimpinnya, senang berada di zona aman, takut melakukan terobosanterobosan baru yang terkadang memiliki resiko. Sehingga sekolah tersebut lambat berubah kearah kemajuan dan kualitas pendidikannnya rendah.

Berpegang erat kepada nilai-nilai spiritual harus dimiliki oleh seorang kepala sekolah yang menjadi figur yang diteladani di sekolah. Tapi pada kenyataannya, masih ada kepala sekolah yang belum dapat dijadikan panutan. Gejala-gejala lain yang ditemukan, masih ada kepala sekolah dalam menjalankan tugasnya, tidak dapat membangun tim kerja yang efektif dan suasana kerja di sekolah tidak kondusif. 
Masih ada kepala sekolah yang belum mau berinovasi dan proaktif dalam menghadapi tantangan kemajuan jaman di era digital. Salah satu penyebabnya adalah kurangnya wawasan atau pengetahuan kepala sekolah. Selain itu hasil uji kompetensi kepala sekolah yang dilaksanakan pada 2015 terhadap 166.333 orang kepala sekolah dari jenjang SDSMK/SMA di seluruh provinsi di Indonesia menunjukkan bahwa nilai UKKS didapatkan pada jenjang SMA $(51,75)$, disusul SMK $(50,67)$, SMP $(50,26)$, dan SD $(44,43)$ (News Okezone.com, 2015). Hasil ini sejalan dengan hasil uji kompetensi guru di mana guru SD cenderung memiliki kompetensi lebih rendah dibandingkan dengan jenjang di atasnya. Dari uji kompetensi itu pula diketahui bahwa ditinjau dari masa kerja, masa kerja 1- 4 tahun memiliki skor lebih tinggi yaitu 46,41, masa kerja 9-12 tahun memiliki skor 45,47, dan masa kerja melebihi 12 tahun memiliki skor 42,78. Dengan kata lain bahwa semakin rendah jenjang sekolah, semakin rendah pula skor kompetensi kepala sekolah dan semakin lama masa kerja kepala sekolah juga semakin rendah kompetensinya. Sejalan dengan itu penelitian yang menunjukkan bahwa skor rerata kompetensi kepala sekolah hanya 45,53 dari rentang 0-100 (Arismunandar, Nurhikmah, \& Ahmad, 2013: 9). Rendahnya kompetensi kepala sekolah hanyalah salah satu masalah yang dihadapi oleh jabatan kepala sekolah di Indonesia.

Kepemimpinan visoner kepala sekolah dapat ditentukan oleh beberapa variabel. Namun berdasarkan gejalagejala yang dikemukakan, maka variabel literasi digital dan optimisme menjadi sangat menarik untuk dilihat pengaruhnya terhadap kepemimpinan visioner kepala sekolah. Literasi digital diperlukan dalam kepemimpinan kepala sekolah karena di era Revolusi Industri
4.0 informasi disajikan secara digital yang menuntut kemampuan literasi digital kepala sekolah. Literasi digital kepala sekolah akan mempengaruhi wawasan dan pola pikir kepala sekolah dalam memimpin sekolahnya.

Menariknya optimisme dalam kaitan pengaruhnya terhadap kepemimpinan visioner kepala sekolah adalah sifat optimisme akan berwawasan ke depan, karena dengan sifat optimisme kepala sekolah memiliki keyakinan akan dapat mencapai cita-cita (visi) yang diharapkan. Selain itu, kepala sekolah yang optimisme, akan menjadi agen perubahan yang tangguh, berani menghadapi resiko dan mampu berinovasi dan proaktif.

Berkenaan dengan hal itu, maka literasi digital dan optimisme kepala sekolah sangat menarik untuk dikaji dan dilihat pengaruhnya terhadap kepemimpinan visioner kepala sekolah. Kepala sekolah yang dimaksudkan adalah Kepala SMP di Kota Pekanbaru.

\section{PERUMUSAN MASALAH}

Merujuk pada latar belakang, maka perumusan, masalah pada penelitian ini adalah:

1. Apakah terdapat pengaruh signifikan antara literasi digital terhadap kepemimpinan visioner kepala SMP di Kota Pekanbaru?

2. Apakah terdapat pengaruh signifikan antara optimisme terhadap kepemimpinan visioner kepala SMP di Kota Pekanbaru?

3. Apakah terdapat pengaruh signifikan antara literasi digital dan optimisme secara bersama-sama terhadap kepemimpinan visioner kepala SMP di Kota Pekanbaru?

\section{TUJUAN PENELITIAN}

Mencermati uraian-uraian latar belakang, perumusan masalah, berlandaskan kajian teori dan arahan 
kerangka berpikir, serta hipotesis penelitian, maka tujuan penelitian ini adalah:

1. Untuk mengetahui dan menganalisis pengaruh antara literasi digital terhadap kepemimpinan visioner kepala SMP di Kota Pekanbaru.

2. Untuk mengetahui dan menganalisis pengaruh antara optimisme terhadap kepemimpinan visioner kepala SMP di Kota Pekanbaru.

3. Untuk mengetahui dan menganalisis pengaruh antara literasi digital dan optimisme secara bersama-sama terhadap kepemimpinan visoner kepala SMP di Kota Pekanbaru.

\section{METODOLOGI PENELITIAN}

Penelitan ini dilaksanakan terhadap Kepala Sekolah Menengah Pertama yang berada di Kota Pekanbaru. Populasi dalam penelitian ini adalah seluruh Kepala SMP di Kota Pekanbaru yang terdiri dari 141 orang (45 orang Kepala SMP Negeri dan 96 orang kepala SMP Swasta di Kota Pekanbaru.

Sampel merupakan subset dari populasi, terdiri dari beberapa anggota populasi. Pengambilan sampel dalam penelitian ini menggunakan teknik Simple Random Sampling, dimana jumlah sampel dalam penelitian ini ditentukan menggunakan rumus Slovin dengan taraf kesalahan 5\% (Sugiyono, 2015: 86), sehingga diperoleh sampel 105 orang.

Teknik pengumpulan data yang digunakan dalam penelitian ini adalah menggunakan survei, maka teknik pengumpulan data yang digunakan adalah instumen berupa kuisioner (angket). Instrumen dari variabel penelitian tersebut sebelum digunakan terlebih dahulu dilakukan uji coba. Uji coba instrumen dilakukan untuk menentukan validitas dan reliabilitas.

Penelitian ini menggunakan teknik analisis statistik deskriptif dan analisis statistik inferensial. Analisis statistik deskriptif dilakukan untuk memaparkan data dalam bentuk distribusi Mean hasil angket. Analisis statistik inferensial digunakan untuk melakukan pengujian terhadap hipotesis hingga sampai pada suatu kesimpulan. Analisis ini diawali dengan uji asumsi klasik yang terdiri dari uji normalitas, uji linieritas, uji multikolinearitas, uji heteroskedastisitas dan uji autokorelasi. Pengujian hipotesis dilakukan dengan melakukan uji regresi sederhana dan regresi berganda.

\section{HASIL PENELITIAN \\ PEMBAHASAN \\ Tabel Nilai Mean Variabel \\ Kepemimpinan Visioner $\mathbf{Y}$ \\ Berdasarkan Indikator}

\begin{tabular}{clcc}
\hline No & \multicolumn{1}{c}{ Indikator } & Mean & Tafsiran \\
\hline 1 & Berwawasan Ke depan & 3,90 & Tinggi \\
\hline 2 & $\begin{array}{l}\text { Menjadi Agen Perubahan } \\
\text { Yang Unggul }\end{array}$ & 4,34 & $\begin{array}{c}\text { Sangat } \\
\text { Tinggi }\end{array}$ \\
\hline 3 & Berani Menghadapi Resiko & 3,99 & Tinggi \\
\hline \multirow{2}{*}{4} & $\begin{array}{l}\text { Berpegang Erat Pada Nilai- } \\
\text { Nilai Spiritual }\end{array}$ & 4,05 & Tinggi \\
\hline \multirow{2}{*}{5} & $\begin{array}{l}\text { Membangun Kerjasama Tim } \\
\text { Efektif }\end{array}$ & 4,33 & $\begin{array}{c}\text { Sangat } \\
\text { Tinggi }\end{array}$ \\
\hline 6 & Inovatif Dan Proaktif & 4,08 & Tinggi \\
\hline & Rata-rata & 4,10 & Tinggi \\
\hline
\end{tabular}

Analisis statistik deskriptif dapat dijelaskan bahwa nilai mean (nilai ratarata indikator) untuk variabel kepemimpinan visioner adalah 4,10. Hal ini menunjukan bahwa Kepemimpinan visioner Kepala SMP di Kota Pekanbaru berdasarkan masing-masing indikator sudah termasuk dalam kategori tinggi. Namun demikian masih perlu peningkatan pada indikator terendah, yaitu berwawasan ke depan (mean = 3,90 ) dan berani menghadapi resko (mean $=3,99$ ) dengan meningkatkan wawasan pengetahuan dan kemauan untuk mampu menghadapi resiko.

\section{Tabel Nilai Mean Variabel Literasi Digital $X_{1}$ Berdasarkan Indikator}

\begin{tabular}{cccc}
\hline No & Indikator & Mean & Tafsiran \\
\hline 1 & Kemampuan Dasar Litarasi & 3,72 & Tinggi \\
\hline 2 & Latar Belakang Pengetahuan & 3,44 & Tinggi \\
\hline
\end{tabular}




\begin{tabular}{clcc}
\hline 3 & Kompetensi Utama Literasi & 3,66 & Tinggi \\
\hline \multirow{2}{*}{4} & $\begin{array}{l}\text { Sikap dan Perspektif } \\
\text { Pengguna Informasi }\end{array}$ & 3,88 & Tinggi \\
\hline$\quad$ Rata-Rata & $\mathbf{3 , 6 8}$ & Tinggi \\
\hline
\end{tabular}

Analisis statistik deskriptif dapat dijelaskan bahwa nilai mean (nilai ratarata indikator) untuk variabel literasi digital adalah 3,68. Hal ini menunjukan bahwa literasi digital Kepala SMP di Kota Pekanbaru berdasarkan masingmasing indikator berada dalam masih kategori tinggi. Meskipun demikian masih perlu peningkatan pada setiap indikator terutama indikator latar belakang pengetahuan dengan nilai terendah $($ mean $=3,44)$ dengan cara mengikuti perkembangan informasi digital saat ini melalui pelatihan ataupun belajar mendiri.

\section{Tabel Nilai Mean Variabel Optimisme} $\mathbf{X}_{2}$ Berdasarkan Indikator

\begin{tabular}{clcc}
\hline No & \multicolumn{1}{c}{ Indikator } & Mean & Tafsiran \\
\hline 1 & Permanence & 3,80 & Tinggi \\
\hline 2 & Pervasiveness & 3,46 & Tinggi \\
\hline 3 & Personalization & 2,95 & Sedang \\
\hline & Rata-Rata & $\mathbf{3 , 5 6}$ & Tinggi
\end{tabular}

Analisis statistik deskriptif dapat dijelaskan bahwa nilai mean (nilai ratarata indikator) untuk variabel optimisme adalah 3,56. Hal ini menunjukan bahwa optimisme Kepala SMP Kota Pekanbaru berdasarkan masing-masing indikator termasuk dalam kategori masih tinggi. Karena itu masih perlu peningkatan pada setiap indikator terutama personalization dengan nilai terendah $($ mean $=2,95)$ dapat dilakukan dengan cara meningkatkan keyakinan diri melalui beragam latihan mandiri dan bersama tim (kelompok MKKS).

Tabel Nilai Mean berdasarkan Masingmasing Variabel Penelitian

\begin{tabular}{clcc}
\hline No & \multicolumn{1}{c}{ Variabel } & Mean & Tafsiran \\
\hline 1 & Kepemimpinan Visioner $Y$ & $\mathbf{4 , 1 0}$ & Tinggi \\
2 & Literasi Digital $X_{1}$ & $\mathbf{3 , 6 8}$ & Tinggi \\
3 & Optimisme $X_{2}$ & $\mathbf{3 , 5 6}$ & Tinggi \\
\hline & Jumlah/Rata-rata & $\mathbf{3 , 7 2}$ & Tinggi \\
\hline
\end{tabular}

Analisis statistik deskriptif diperoleh data untuk nilai mean berdasarkan masingmasing variabel penelitian. Nilai tertinggi terdapat pada variabel kepemimpinan visioner (mean $=4,10)$, kemudian variabel literasi digital (mean $=3,68)$, dan variabel optimisme (mean= 3,56). Dengan demikian dapat disimpulkan bahwa tingkat kepemimpinan visioner, literasi digital, dan optimisme berada pada kategori masih tinggi (mean= 3,72).

Pengujian hipotesis, mencari pengaruh antar variabel dapat dilihat: a) diperoleh pengaruh yang signifikan antara variabel literasi digital terhadap kepemimpinan visioner Kepala SMP di Kota Pekanbaru adalah 31,30\%, b) diperoleh pengaruh variabel optimisme terhadap kepemimpinan visioner Kepala SMP di Kota Pekanbaru adalah 21,80\%, c) diperoleh pengaruh variabel literasi digital dan optimisme secara bersamasama terhadap kepemimpinan visioner Kepala SMP di Kota Pekanbaru adalah $37,7 \%$.

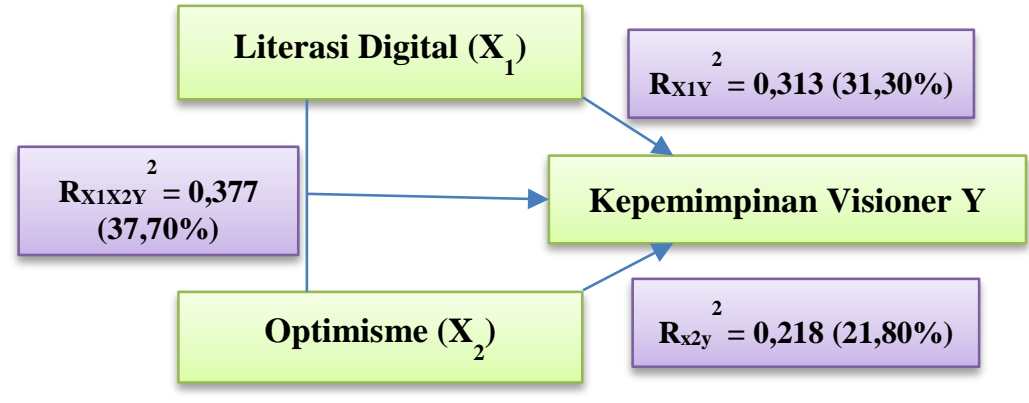

\section{SIMPULAN}

Berdasarkan hasil penelitian maka dapat disimpulkan beberapa hal sebagai berikut.

Pertama, terdapat pengaruh yang signifikan antara literasi digital $\left(\mathrm{X}_{1}\right)$ terhadap kepemimpinan visioner (Y). Semakin tinggi literasi digital maka semakin tinggi pula kepemimpinan visioner kepala sekolah. Hal ini bermakna bahwa kepala sekolah mampu 
meningkatkan literasi digital untuk meningkatkan wawasan pengetahuan dengan cara meningkatkan kemampuaan dasar literasi, latar belakang pengetahuan, kompetensi utama literasi dan sikap dan perspektif pengguna informasi.

Kedua, terdapat pengaruh yang signifikan optimisme $\left(\mathrm{X}_{2}\right)$ terhadap kepemimpinan visioner kepala sekolah. (Y). Semakin tinggi optimisme yang dimiliki kepala sekolah maka semakin tinggi pula kepemimpinan visioner kepala sekolah. Hal ini bermakna bahwa kepala sekolah mampu meningkatkan optimisme atau untuk bekerja sama mencapai tujuan yang diinginkan, dengan cara meningkatkan permanence, pervasiveness dan personalization.

Ketiga, Terdapat pengaruh yang signifikan literasi digital $\left(\mathrm{X}_{1}\right)$ dan optimisme $\left(\mathrm{X}_{2}\right)$ secara bersama-sama terhadap kepemimpinan visioner kepala sekolah (Y). Semakin tinggi literasi digital dan optimisme maka semakin tinggi pula kepemimpinan visioner kepala sekolah. Hal ini bermakna bahwa kepala sekolah mampu meningkatkan kepemimpinan visiner dengan cara meningkatkan berwawasan kedepan, menjadi agen perubahan yang unggul, berani menghadapi resiko, berpegang erat pada nilai-nilai spiritual, membangun kerjasama tim efektif dan inovatis dan proaktif.

\section{UCAPAN TERIMA KASIH}

Pada akhirnya, penulis menyadari bahwaartikel ini tidak akan selesai tanpa dukungan dari rekan-rekan Dinas Pendidikan Kota Pekanbaru atas segala bantuan dan dukungan yang telah diberikan.

\section{DAFTAR PUSTAKA}

Aan Komariah dan Triatna. 2016. Visionary Leadership Menuju Sekolah Efektif, Bumi Aksara, Jakarta.
Achmad Sanusi, 2009. Kepemimpinan Sekarang dan Masa Depan dalam Membentuk Budaya Organisasi yang Efektif, Prospect, Bandung.

Adair, J, 2003. Effective Innovation: How to Stay Ahead of the Competition, Pan Books Ltd, London.

Afid Burhanuddin, 2014, Teori-teori Kepemimpinan, (online) https://afidburhanuddin.wordpress.c om/2014/01/20/teori-teori-

kepemimpin an, diakses 4 Januari 2020.

Agung Webe, 2018, Memaknai Kembali Literasi, https://www.kompasiana.com/agung webe/5a8dcf2ecaf7db2ea4098012/m emaknai-kembali-literasi?page $=$ all, diakses 10 Januari 2020.

Akhras, Caroline, 2016, Rethinking Leadership--Digital Literacy and Authenticit. Proceedings of Society for Information Technology \& Teacher Education International Conference. March 21-26, 2016, Savannah, GA, United States,

Andar Hutagalung, 2019, Pentingnya Membangun Pengetahuan Literasi Digital Terutama Pada Bidang Akademik, Buletin Konsorsium Psikologi Ilmiah Nasional. Vol.5 No. 3, Fakultas Psikologi Universitas Sumatera Utara, Medan.

Badan Akreditasi Nasional Sekolah dan Madrasah (BANSM). 2020. Data Akreditasi Sekolah, https://bansm.kemdikbud.go.id/akre ditasi, diakses 20 Juli 2020.

Bawden, D, 2008, Origins and Concepts of Digital Literacy, in: Digital 
Literacies: Concepts, Policies and Practices, Peter Lang Publishing, New York.

Burt Nanus, 2012. Kepemimpinan Visioner, Prehalindo, Jakarta.

Erni Trisnawati Sule dan Donni Juni Priansa, 2018. Kepemimpinan dan Perilaku organisasi: Membangun Organisasi Unggul di Era Perubahan, PT. Refika Aditama, Bandung.

Fandy Tjiptono, 2015. Strategi Pemasaran. Edisi Keempat, Andi Ofset, Yogyakarta.

Gilster, P, 1997. Digital Literacy, John Wiley \& Sons, Inc, New York.

Goleman, D. 1999. Kecerdasan Emosi untuk Mencapai Puncak Prestasi.: Gramedia Pustaka Utama, Jakarta.

Gufron dan Risnawati. 2010. Teori-Teori Psikologi, Ar-Ruzz Media Group Yogyakarta.

Gujarati, D.N., 2015. Dasar-Dasar Ekonometrika. Buku II. Edisi Kelima, Salemba Empat, Jakarta Selatan.

Hafied Cangara, 2015. Pengantar Ilmu Komunikasi. Cetakan Kedua, PT. RajaGrafindo Persada, Jakarta.

Hague, C \& Payton, S., 2010, Digital Literacy Across The Curriculum, (online)

https://www.nfer.ac.uk/publications/ FUTL06, diakses 13 Januar 2020.

Hall, D. K. 2000. Fostering optimisme in young children, Ideas, Toronto.
Hair, et.al. 2018. Multivariate Data Analysis (8th ed), Pearson, United States.

Hillson, D.A. \& Murray-WR. 2005. Understanding and Managing Risk Attitude. Gower, Aldershot, UK..

Hobbs, R., 2010, Digital and Media Literacy, A Plan of Action, Journal of Craniofacial Surgery (Vol. 23), The Aspen Institute. United States of Amerika.

Nurul Hidayah, 2016. Kepemimpinan Visioner Kepala Sekolah; Dalam Meningkatkan Mutu Pendidikan, ArRuzz media, Jakarta.

Ivancevich, J,M., Robert K dan Michael T. M, 2008. Organizations Behavior and Management, 8nd Edition, McGraw-Hill/Irwin, Singapore.

Marno dan Triyo Supriyatno, 2013. Manajemen Dan Kepemimpinan Pendidikan Islam, PT Refika Aditama, Jakarta.

Martin, A., 2006, Literacies for Age Digital Age dalam Martin \& D. Madigan (eds), Digital Literacies for Learning, Facet Publishing, London.

McGinnis, A.L. 1995. Kekuatan Optimisme, Mitra Utama, Jakarta.

Nanus, Burt., 1999. Leaders Who Make a Diffrence for Meeting the non-Profit Challenge. San Francisco

Norrish, J., Robinson, J. Dan Williams, P. 2011. Positive health. Literature Reviews. Institute Of Positive Education, Victoria. 
Parker, D, 2006. Menumbuhkan Kemandirian dan Harga Diri Anak, Prestasi Pustakaraya, Jakarta.

Parker, Deboar K, 2006, Menumbuhkan Kemandirian Dan Harga Diri Anak, Prestasi Pustakarya, Jakarta.

Peraturan Mendiknas RI Nomor 22 Tahun 2020 tentang Renstra Kementrian Pendidikan dan Kebudayaan 2020-2024

Raka, G, dkk., 2011. Pendidikan Karakter di Sekolah: Dari Gagasan ke Tindakan, PT. Gramedia, Jakarta.

Riduwan, 2011. Dasar-Dasar Statistika, Alfabeta, Bandung.

Risnawati, R. \& Ghufron, M.N., 2010. Teori-Teori Psikologi, ArRuzz Media Group, Yogyakarta.

Seligman, Martin. 2008. Menginstal Optimisme (Edisi Terjemahan). Translated by Budhy Yogapranata. 2008, PT Karya Kita, Bandung.

Slamet Santoso, 2004. Dinamika Kelompok Sosial, Bumi Aksara, Bandung.

Soerjono Soekanto, 1992. Kamus Sosiologi, PT. Raja Grafindo Persada, Jakarta.

Suharsimi Arikunto, 2016. Prosedur Penelitian Suatu Pendekatan Praktik, Rineka Cipta, Jakarta.

Sugiyono, 2015. Metode Penelitian dan Pengembangan: Research and Development, Alfabeta, Bandung.

Sutarjo Adisusilo, 2012. Pembelajaran Nilai-Karakter, PT. Raja Grafindo Persada, Jakarta.
Syamsu Yusuf dan Juntika Nurihsan, 2011. Teori Kepribadian, PT. Remaja Rosdakarya Offset, Bandung.

Tatang Syarifudin dan Kurniasih. 2013. Filsafat dan Pendidikan. Percikan Ilmu, Bandung.

Tatty Rosmiyati dan Dedy Achmad Kurniadi. 2011. Manajemen Pendidikan, Alfabeta, Bandung.

Veitzhal Rivai dan Ariviyan Arifin, 2009. Islamic Leadership Membangun Superleadership Melalui Kecerdasan Spiritual, Bumi Aksara, Jakarta.

Wahyudi, 2015. Kepemimpinan Kepala Sekolah dalam Organisasi Pembelajaran, Alfabeta, Bandung.

Wibowo, 2018. Manajemen Perubahan, PT Raja Grafindo Persada, Jakarta.

Yates, J. F. 1992. Judgement And Decision Making, Prentice Hall, Englewood Cliffs.

Yukl, G, 2009. Leadership In Organization. (terjemahan Budi Supriyanto) Edisi Kelima, Macan Jaya Cemerlang, Jakarta:

Zulkarimein Nasution, 1990. PrinsipPrinsip Komunikasi untuk Penyuluhan. Fakultas Ekonomi Universitas Indonesia, Jakarta. 